This is the author's final, peer-reviewed manuscript as accepted for publication. The publisher-formatted version may be available through the publisher's web site or your institution's library.

\title{
An experimental investigation on slicing of potassium dihydrogen phosphate (KDP) crystal
}

Q. G. Wang, H. Gao, Z. J. Pei, D. M. Guo, X. J. Teng

\section{How to cite this manuscript}

If you make reference to this version of the manuscript, use the following information:

Wang, Q. G., Gao, H., Pei, Z. J., Guo, D. M., \& Teng, X. J. (2013). An experimental investigation on slicing of potassium dihydrogen phosphate (KDP) crystal. Retrieved from http://krex.ksu.edu

\section{Published Version Information}

Citation: Wang, Q. G., Gao, H., Pei, Z. J., Guo, D. M., \& Teng, X. J. (2013). An experimental investigation on slicing of potassium dihydrogen phosphate (KDP) crystal. Proceedings of the Institution of Mechanical Engineers Part B-Journal of Engineering Manufacture, 227(6), 890-897.

Copyright: Copyright (c 2013 by Institution of Mechanical Engineers

Digital Object Identifier (DOI): doi:10.1177/0954405413478263

Publisher's Link: http://pib.sagepub.com/content/227/6/890.abstract

This item was retrieved from the K-State Research Exchange (K-REx), the institutional repository of Kansas State University. K-REx is available at http://krex.ksu.edu 


\title{
An Experimental Investigation on Slicing of Potassium Dihydrogen Phosphate (KDP) Crystal
}

\author{
Q.G. Wang ${ }^{1}$, H. Gao ${ }^{1}$, Z.J. Pei $^{2}$, D.M. Guo ${ }^{1}$, X.J. Teng ${ }^{1}$ \\ ${ }^{1}$ Department of Mechanical Manufacturing and its Automation, Key Laboratory of the \\ Ministry of Education for Precision and Non-Traditional Machining Technology, Dalian \\ University of Technology, Dalian, China, 116024 \\ ${ }^{2}$ Dept of Industrial and Manufacturing Systems Engineering, Kansas State University, \\ Manhattan, KS, USA, 66506 \\ e-mail: doughty_w@sohu.com (Q.G. Wang)
}

\begin{abstract}
Because of its unique properties, potassium dihydrogen phosphate (KDP) crystals are widely used for electro-optical applications. Slicing is needed to make KDP crystal lens with desired shapes. However, reported studies on slicing of KDP crystal are scarce. This paper presents an experimental investigation on slicing of KDP crystals. Output parameters studied include surface roughness, flatness error, parallelism error, and subsurface damage. Effects of wire sawing input variables (feed rate and diamond grit size) on output parameters are investigated. Comparisons of wire sawing and band sawing are also made.
\end{abstract}

Keywords: flatness error; KDP crystal; slicing; subsurface damage; surface quality; wire sawing. 


\section{Introduction}

Because of its unique properties, potassium dihydrogen phosphate (KDP) crystals are widely used for electro-optical applications [1-3]. For example, large KDP crystal parts (with a size of $410 \mathrm{~mm} \times 410 \mathrm{~mm} \times 10 \mathrm{~mm}$ ) are used as optical harmonic generation lens and Pockels electro-optic switches for the application of inertial confinement fusion $[4,5]$.

Table 1 lists some mechanical properties of KDP in comparison with three commonly used materials (tool steel, alumina, and silicon carbide). It shows that KDP has much lower hardness and fracture toughness. In addition, KDP is deliquescent. All these make it a difficult-to-machine material [6-8].

Table 1. Mechanical properties of KDP in comparison with other materials $[5,9,10]$

\begin{tabular}{lcccc}
\hline \hline Property & KDP & Tool steel & Alumina & Silicon carbide \\
\hline Hardness (Mohs) & 2.5 & 6.5 & 9 & $9 \sim 10$ \\
Elastic modulus $(\mathrm{GPa})$ & 63 & 207 & 380 & 476 \\
Fracture toughness $\left(\mathrm{MPa} \times \mathrm{m}^{1 / 2}\right)$ & 0.1 & $50 \sim 80$ & 4.2 & 4.0 \\
\hline \hline
\end{tabular}

An important machining process for KDP is the slicing of workpieces into desired shapes. Currently, slicing methods include outer diameter (OD) sawing [11], inner diameter (ID) sawing [12], band sawing, and wire sawing [13]. OD sawing uses a thin blade with diamond abrasives plated on its outer diameter. As the blade diameter gets larger, the deflection at the edge of the blade will become larger under the same force. This can cause the blade to vibrate with larger amplitude, resulting in higher kerf loss [11]. Inner diameter sawing uses a hollow blade with diamond abrasives plated on its inner diameter. Compared with OD sawing, ID 
sawing has higher stiffness, lower kerf loss, and better slicing quality. However, the blade stiffness is still a bottleneck when the blade diameter increases to a certain value. This limits its application in slicing large size KDP crystals [14]. Band sawing uses either a steel band saw with teeth or a steel band saw with plated diamond abrasives. Although it has a high kerf loss, this method is still used to slice large size KDP workpieces.

Compared with the aforementioned slicing methods, wire sawing is especially suitable for slicing large KDP crystal materials, primarily due to its lower kerf loss [15]. There are two types of wire sawing, free abrasive and fixed abrasive. In comparison with fixed abrasive wire sawing, free abrasive wire sawing takes longer time to cut the same size of KDP crystals [14]. It has other problems such as embedment of the abrasive particles into KDP workpiece surfaces and the environmental pollution when disposing the used slurry.

Although wire sawing has many advantages in slicing KDP crystal materials [16], there is only one reported study on the subsurface damage in wire sawing of KDP [17]. There are no reported studies about the effects of input variables (such as feed rate and diamond grit size) on workpiece surface profile and subsurface damage in wire sawing of KDP.

This paper reports an experimental investigation using fixed abrasive wire sawing of KDP. Output parameters include surface roughness, flatness error, parallelism error, and subsurface damage. Effects of wire sawing input variables (feed rate and diamond grit size) on output parameters are investigated. Comparisons of wire sawing and band sawing are also made.

\section{Experimental conditions}

\subsection{KDP workpieces}

KDP workpieces were obtained from Shandong University (Jinan, Shandong, China). Two sizes of KDP workpieces were used: $150 \mathrm{~mm} \times 105 \mathrm{~mm} \times 6 \mathrm{~mm}$ and $15 \mathrm{~mm} \times 6 \mathrm{~mm} \times 3 \mathrm{~mm}$. The crystalline surface was (001). 


\subsection{Experimental setup and conditions for wire sawing}

Wire sawing experiments were conducted on a reciprocating diamond wire sawing machine. Figure 1 illustrates the experimental setup schematically.

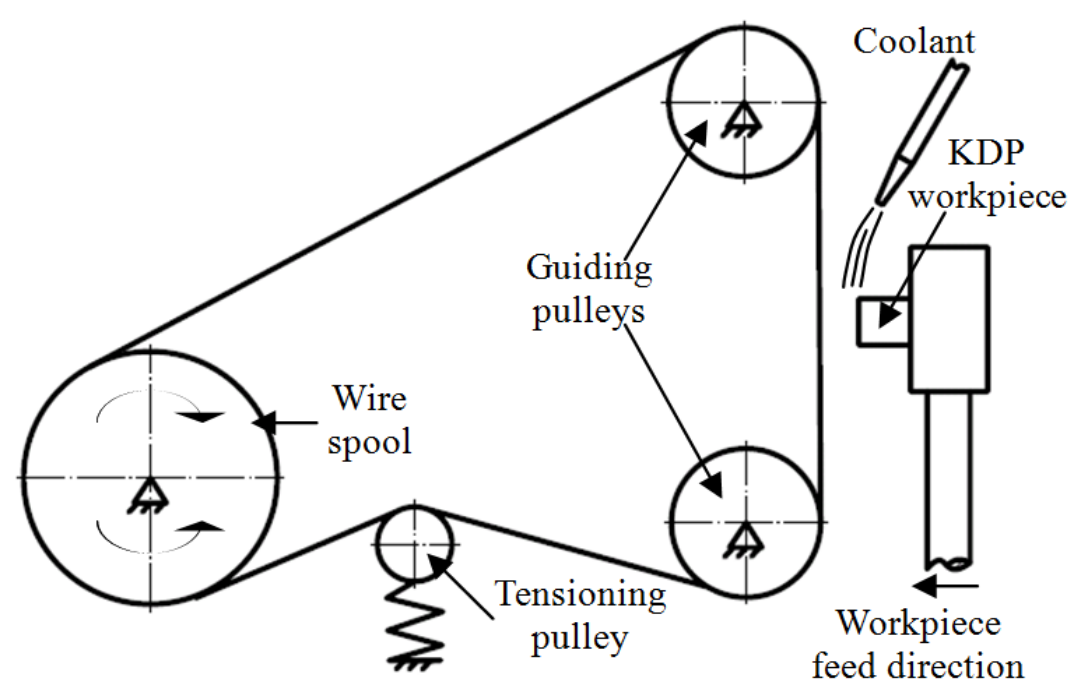

Figure 1 Illustration of wire sawing experimental setup

Two types of diamond plated stainless steel wires were obtained from Kejing Automation Equipment Company (Shenyang, Liaoning Province, China). The first type had diamond grit size of $40 \mu \mathrm{m}$ and wire diameter of $0.3 \mathrm{~mm}$. The second type had diamond grit size of $60 \mu \mathrm{m}$ and wire diameter of $0.4 \mathrm{~mm}$. An SEM picture of the second type is shown in Figure 2. 


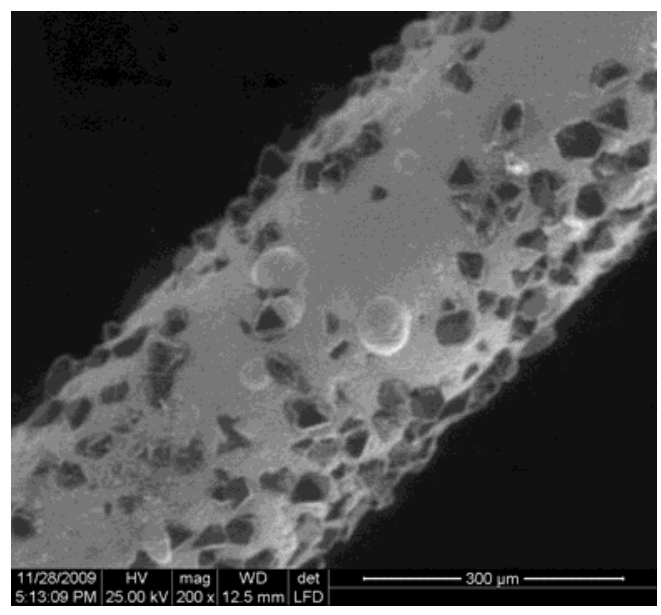

Figure 2 SEM picture of a diamond plated wire $($ diamond grit size $=60 \mu \mathrm{m}$, wire diameter $=0.4 \mathrm{~mm})$

Table 2. Wire sawing input variables and their values

\begin{tabular}{ccc}
\hline \hline Input variable & Unit & Value \\
\hline Feed rate & $\mathrm{mm} / \mathrm{min}$ & $0.2 ; 0.6 ; 1 ; 2$ \\
\hline Diamond grit size & $\mu \mathrm{m}$ & $40 ; 60$ \\
\hline
\end{tabular}

Two input variables (feed rate and diamond grit size) were investigated. Table 2 shows their values used in the wire sawing experiments. Wire speed was $60 \mathrm{~m} / \mathrm{min}$. If the wire length was 65 meters, the reciprocating period would be 135 seconds (including the time for the wire to slow down and change its moving direction). The coolant (mineral lubricant) had a viscosity of less than $10 \mathrm{cSt}$ and was supplied to the slicing area with a flow rate of $180 \mathrm{~mL} / \mathrm{min}$. In order to slice workpiece with good flatness error, the tension stress was selected to be as close as possible to the maximum allowable tension stress while still could maintain a reasonable wire life. The maximum allowable tension stress was determined by prior experiments. A tension stress higher than the maximum tension allowable would result in an early broken of 
the wire. Too low a tension stress would result in a longer wire life but a sliced surface with poor flatness error.

\subsection{Experimental setup and conditions for band sawing}

A vertical band sawing machine (North Tiger, Beijing, China) was used. Its picture is shown in Figure 3. It is capable of sawing workpieces as large as about $500 \mathrm{~mm}$ in height.

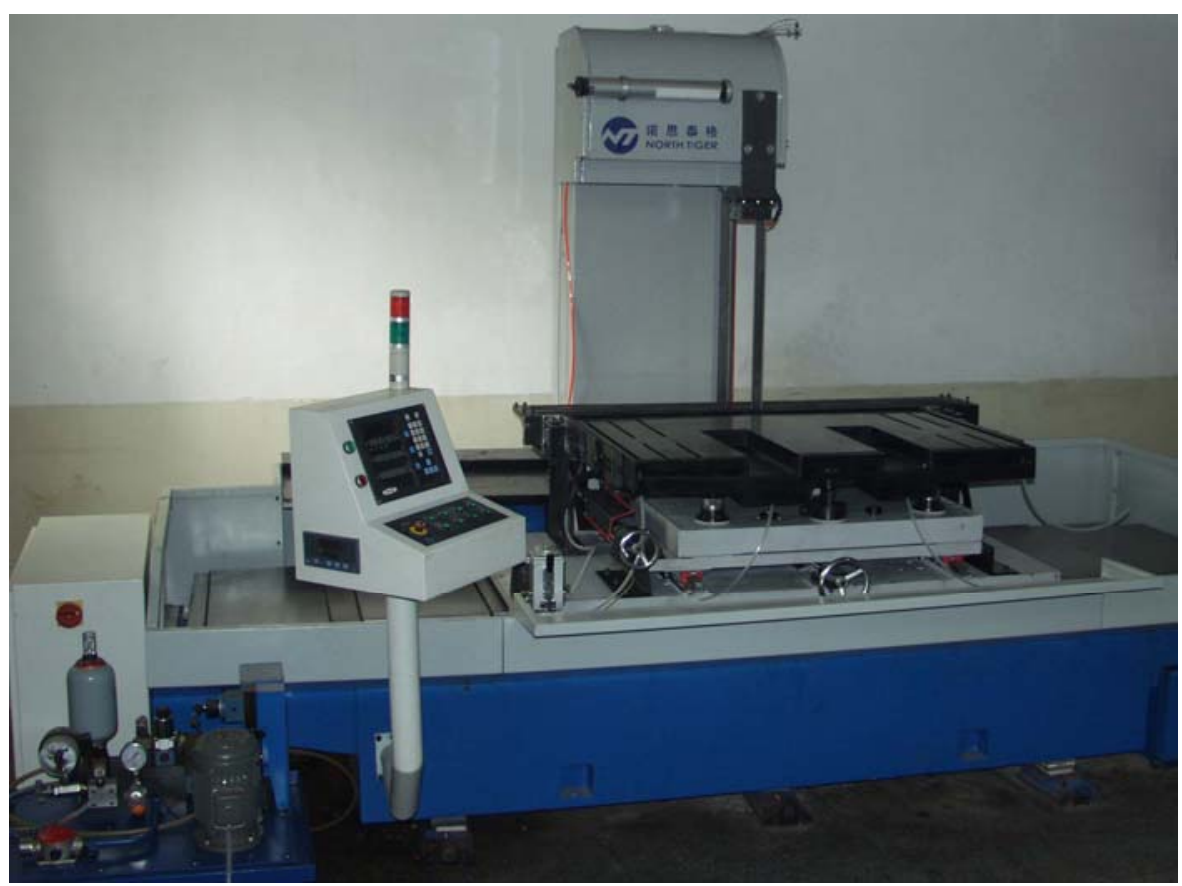

Figure 3 Picture of band sawing machine.

Figure 4 shows the two types of band saws used. One had regular teeth and the TPI (teeth per inch) was 10, and the other had plated diamond abrasives with grit size of $60 \mu \mathrm{m}$. The thickness of these band saws was $1.2 \mathrm{~mm}$ and blade width was $40 \mathrm{~mm}$. When slicing, the band saw moving speed was $120 \mathrm{~m} / \mathrm{min}$, and the feed rate was $1.33 \mathrm{~mm} / \mathrm{min}$. The coolant used was the same as that used in wire sawing. 


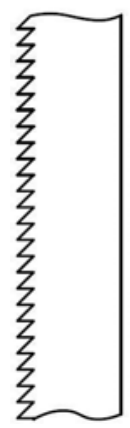

(a) Band saw with teeth

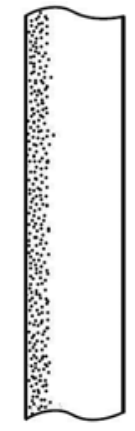

(b) Band saw with plated diamond abrasives

Figure 4 Two types of band saws

\subsection{Measurement procedures}

Surface roughness was measured on sliced surfaces along the feed direction, using a surface profilometer (Talysurf CSI 2000, Taylor Hobson Ltd). The KDP workpiece was fixed on the worktable of the profilometer. Then the probe (diameter of the styles was $1 \mu \mathrm{m}$ ) was adjusted to touch the workpiece surface with very small contact force. Then the worktable started to move at a speed of $0.2 \mathrm{~mm} / \mathrm{s}$ with the cut off distance of $2.5 \mathrm{~mm}$. The surface roughness in this study was characterized by average surface roughness $\mathrm{Ra}$ and the peak-to-valley roughness Rz.

Flatness error measures the deviation of a sliced surface to an ideal surface that is perfectly flat. Parallelism error measures how parallel the two sliced surfaces are. Both flatness and parallelism errors were measured using a Prismo Navigator Measuring Center (model PRISMO7S-ACC, Zeiss, Oberkochen, Germany) at Modern Manufacturing Technology Institute of Dalian University of Technology. 


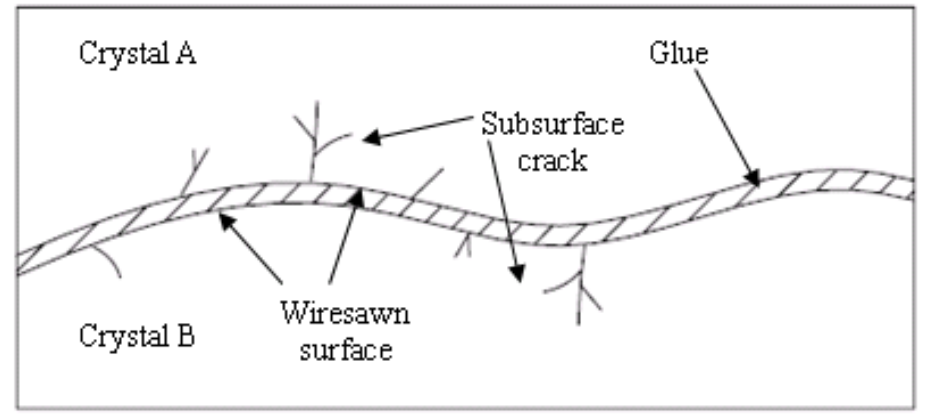

Figure 5 Cross section polishing method for subsurface damage measurement

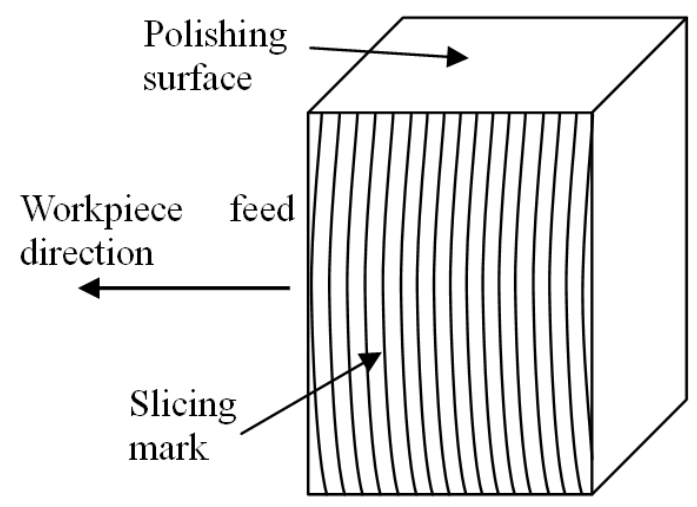

Figure 6. Illustration of polishing surface

Subsurface damage (including dislocations and cracks) was measured by using the cross section polishing and etching methods. As shown in Figure 5, two sliced surfaces (facing each other) were glued together. As illustrated in Figure 6, polishing was done on the surfaces perpendicular to the sliced surfaces and parallel to the workpiece feed direction. The polishing slurry was the mixture of $\mathrm{SiO}_{2}$ (grits size ranged from 7 to $20 \mathrm{~nm}$ ) and alcohol. The polishing pad was black finishing leather rotating at a speed of $80 \mathrm{rev} / \mathrm{min}$. Surface roughness $(\mathrm{Ra})$ of the polished KDP cross section surface was around $5 \mathrm{~nm}$. The etchant was prepared by mixing $60 \mathrm{~mL}$ of glacial acetic acid, $5 \mathrm{~mL}$ of deionized water, and 4 drops of concentrated sulfuric acid. After etching, damaged areas on the polished surface became visible since their etching rate was faster than undamaged ones [18]. 
Figure 7 shows the subsurface damage observed by using the cross section polishing and etching methods. The depth of the deepest crack was the maximum depth of the slicing induced subsurface damage.

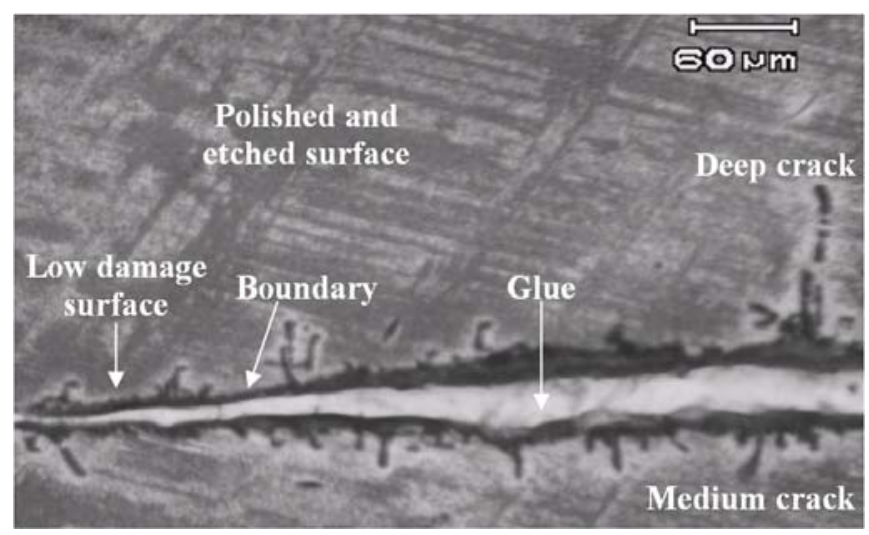

Figure 7 Subsurface damage observed by using the cross section polishing and etching method

\section{Results and discussion}

\subsection{Sliced surface profiles}

Figs. 8 and 9 show the wire sawing sliced surface profiles measured along the workpiece feed direction.

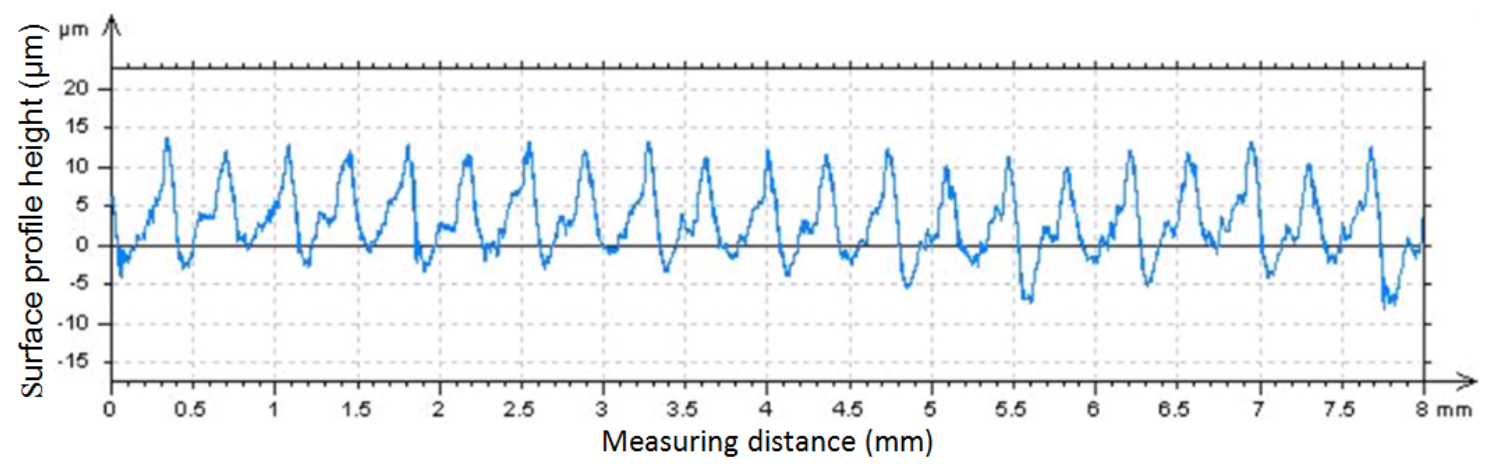

(a) Feed rate $=0.3 \mathrm{~mm} / \mathrm{min}$ 


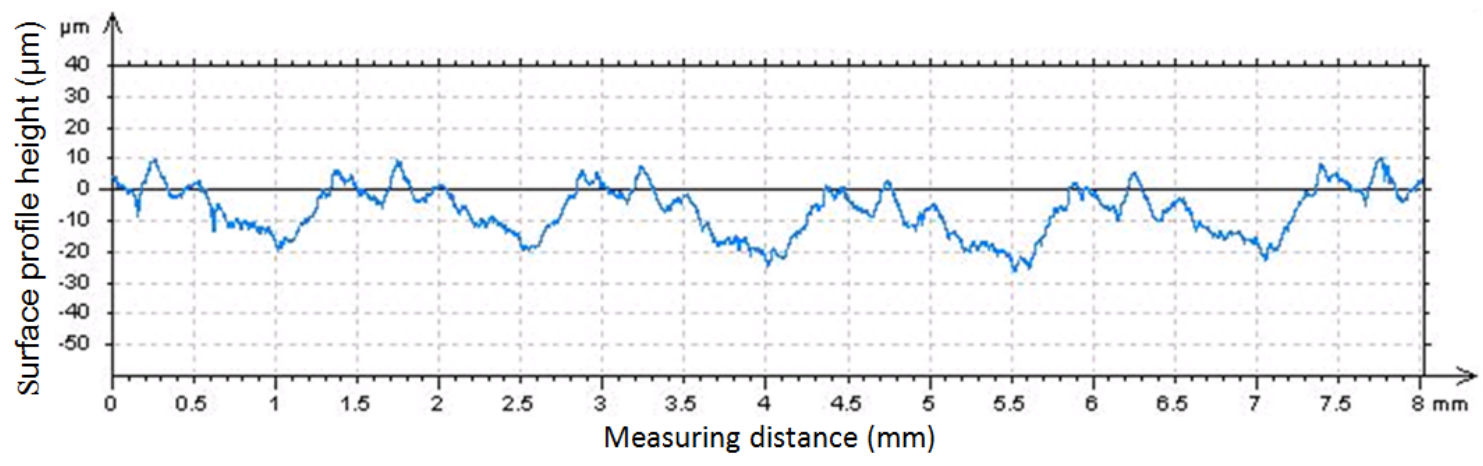

(b) Feed rate $=0.6 \mathrm{~mm} / \mathrm{min}$

Workpiece size $=15 \mathrm{~mm} \times 6 \mathrm{~mm} \times 3 \mathrm{~mm}$, diamond grit size $=40 \mu \mathrm{m}$

\section{Figure 8 Wire sawing sliced surface profiles at different feed rates}

All sliced surface profiles show a periodical feature. Based on the calculated relationship between feed rate and wire sawing reciprocating period, it was found that the periodical feature was caused by the wire sawing reciprocating action (the wire changed its moving direction). For example, the wire that was $65 \mathrm{~m}$ long would need about 135 seconds to finish a cycle of reciprocation (wire speed was $60 \mathrm{~m} / \mathrm{min}$ ). During this period of time, the workpiece was fed about $1.35 \mathrm{~mm}$ (calculated by multiplication of time and feed rate which was 0.6 $\mathrm{mm} / \mathrm{min}$ ), approximately equal to the peak-to-peak distance of the periodical feature shown in Figure 9.

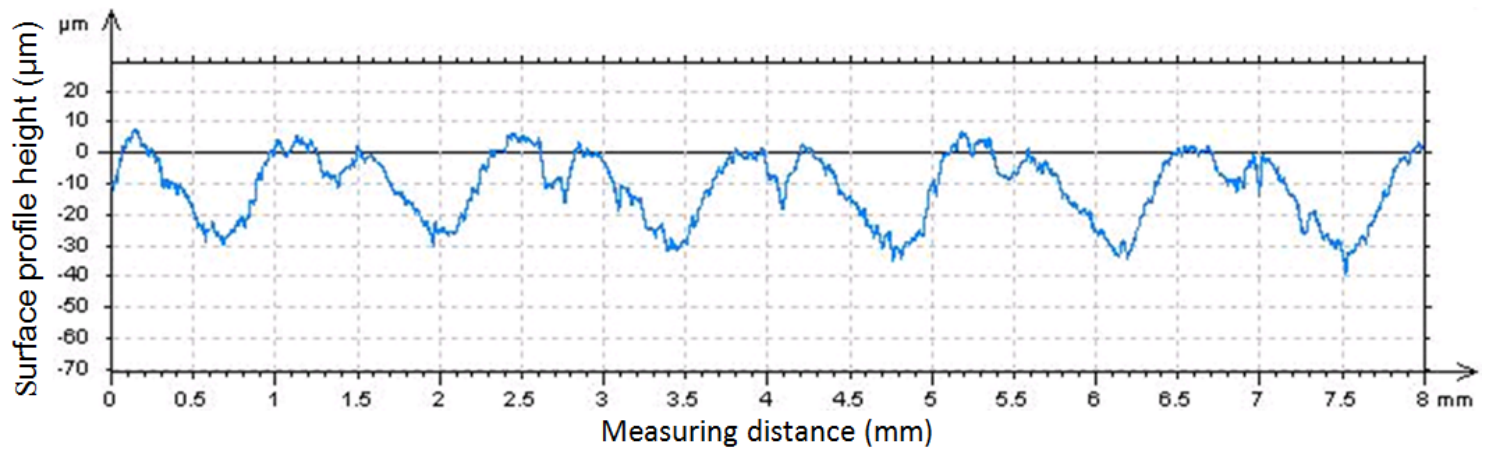


Workpiece size $=15 \mathrm{~mm} \times 6 \mathrm{~mm} \times 3 \mathrm{~mm}$, diamond grit size $=60 \mu \mathrm{m}$

Figure 9 Wire sawing sliced surface profile (feed rate $=0.6 \mathrm{~mm} / \mathrm{min}$ )

\subsection{Surface roughness}

Effects of feed rate on surface roughness in wire sawing of KDP are shown in Figure 10. As feed rate increased from 0.3 to $0.6 \mathrm{~mm} / \mathrm{min}$, both $\mathrm{Ra}$ and $\mathrm{Rz}$ increased, from $\mathrm{Ra}=3.52 \mu \mathrm{m}$ and $\mathrm{Rz}=11.1 \mu \mathrm{m}$ to $\mathrm{Ra}=5.29 \mu \mathrm{m}$ and $\mathrm{Rz}=30 \mu \mathrm{m}$.

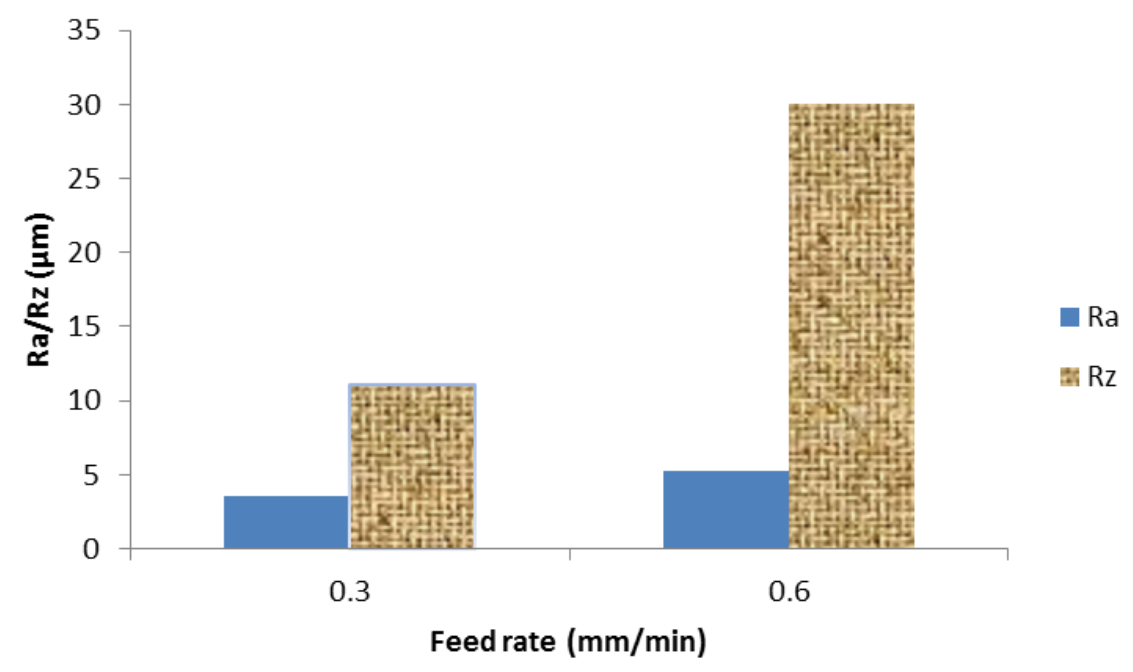

\section{Workpiece size $=15 \mathrm{~mm} \times 6 \mathrm{~mm} \times 3 \mathrm{~mm}$, diamond grit size $=40 \mu \mathrm{m}$, wire speed $=60$ $\mathbf{m} / \mathbf{m i n}$}

Figure 10. Effects of feed rate on surface roughness

Effects of diamond grit size on roughness are shown in Figure 11. Surface roughness Ra and $\mathrm{Rz}$ were higher when larger diamond grits were used. 


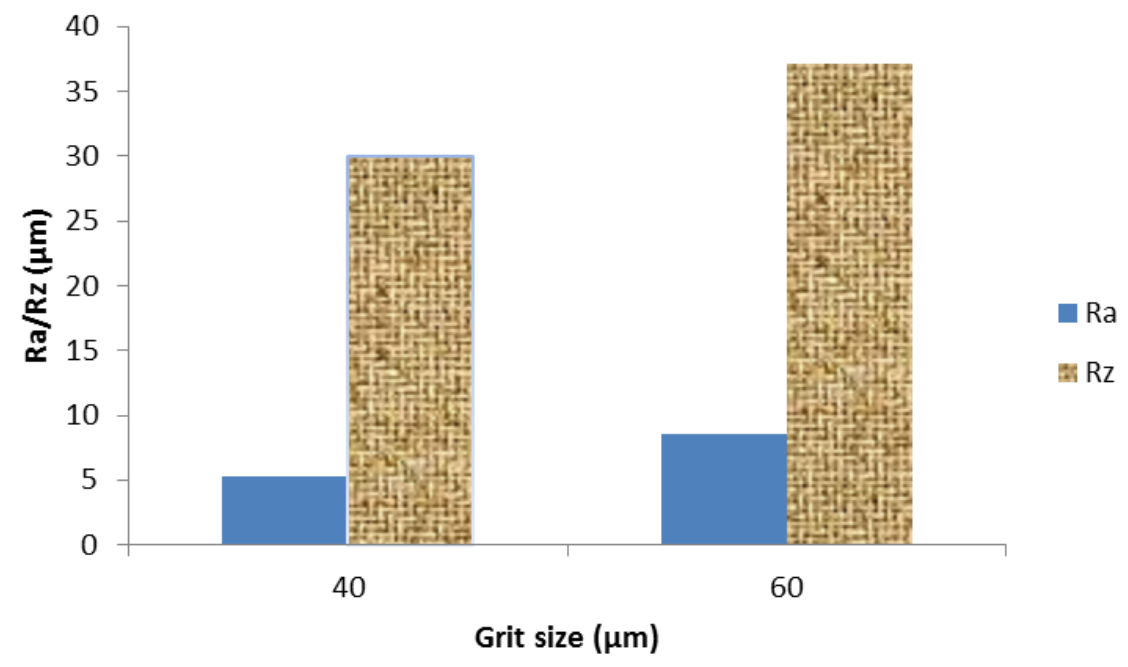
Workpiece size $=15 \mathrm{~mm} \times 6 \mathrm{~mm} \times 3 \mathrm{~mm}$, feed rate $=0.6 \mathrm{~mm} / \mathrm{min}$, wire speed $=60$ $\mathrm{m} / \mathrm{min}$

Figure 11 Effects of diamond grit size on surface roughness $\mathrm{Ra}$ and $\mathrm{Rz}$

\subsection{Flatness and parallelism errors}

Figure 12 shows the effects of feed rate on flatness error in wire sawing. As the feed rate increased, flatness error became higher.

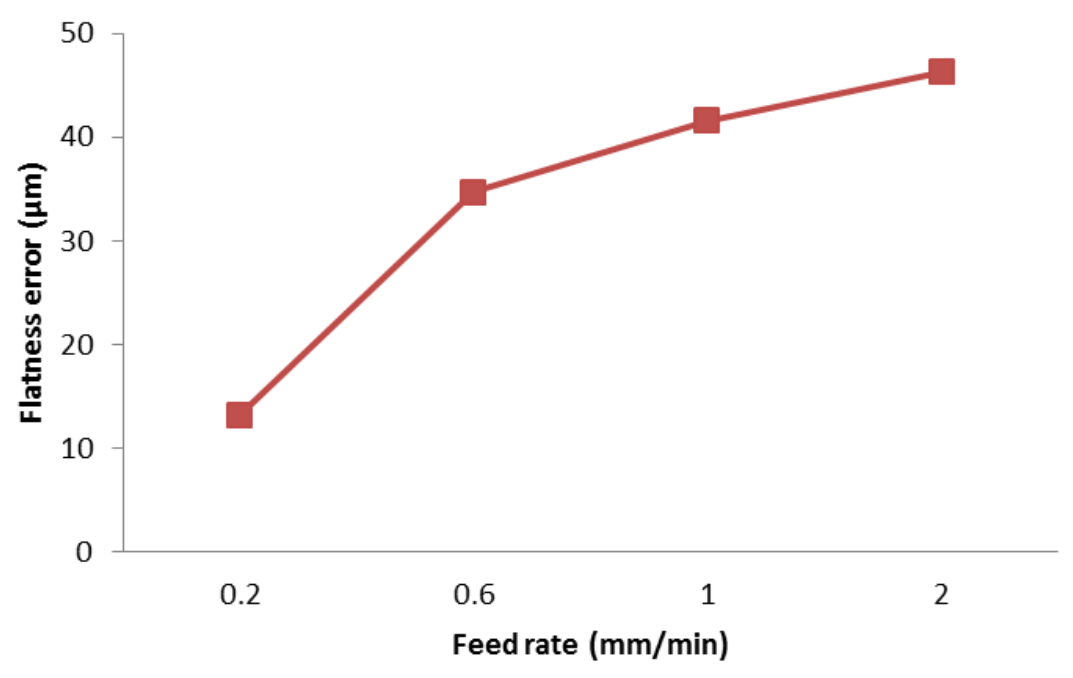


Workpiece size $=15 \mathrm{~mm} \times 6 \mathrm{~mm} \times 3 \mathrm{~mm}$, diamond grit size $=60 \mu \mathrm{m}$, wire speed $=60$ $\mathbf{m} / \mathbf{m i n}$

\section{Figure 12 Effects of feed rate on flatness error}

In wire sawing, as the workpiece is fed towards the wire, the wire in contact with the workpiece bended like a bow string due to the pushing force from the workpiece. Therefore, the slicing marks left on the workpiece surface became curved. Figure 13 is the photograph of a sliced surface showing one curved slicing mark. Before the photograph was taken, the curved slicing mark was traced by a pencil to make it more visible.

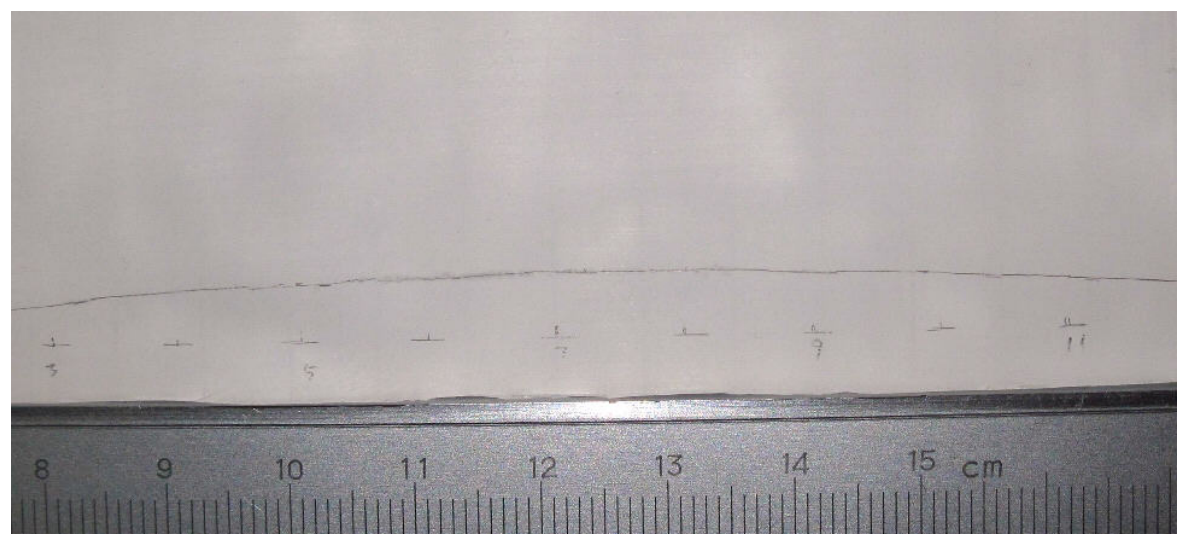

\section{Workpiece $=150 \mathrm{~mm} \times 105 \mathrm{~mm} \times 6 \mathrm{~mm}$, diamond grit size $=40 \mu \mathrm{m}$, feed rate $=0.3$ $\mathbf{m m} / \mathbf{m i n}$}

\section{Figure 13 Curved slicing mark}

To compare the slicing quality between wire sawing and band sawing (using the band saw with teeth), flatness and parallelism errors for sliced workpiece by band sawing were also measured and are shown in Figure 14. Flatness and parallelism errors were $90 \mu \mathrm{m}$ and 1.26 $\mathrm{mm}$, respectively. 


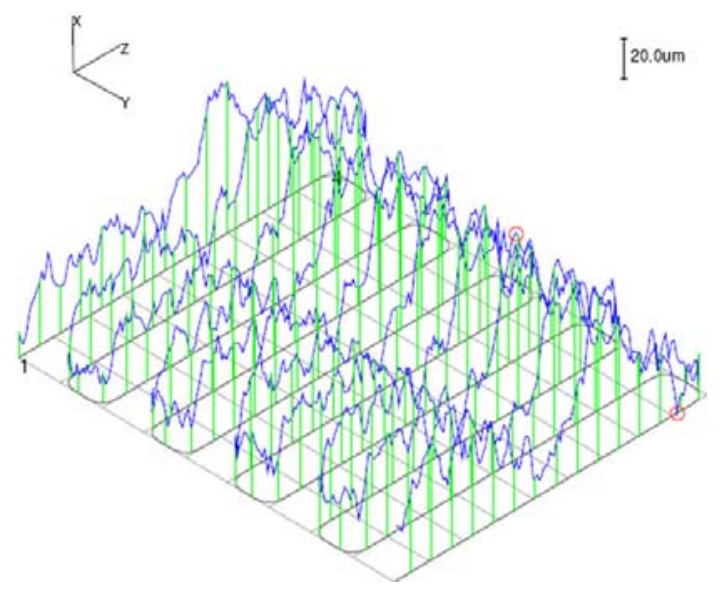

(a) Flatness

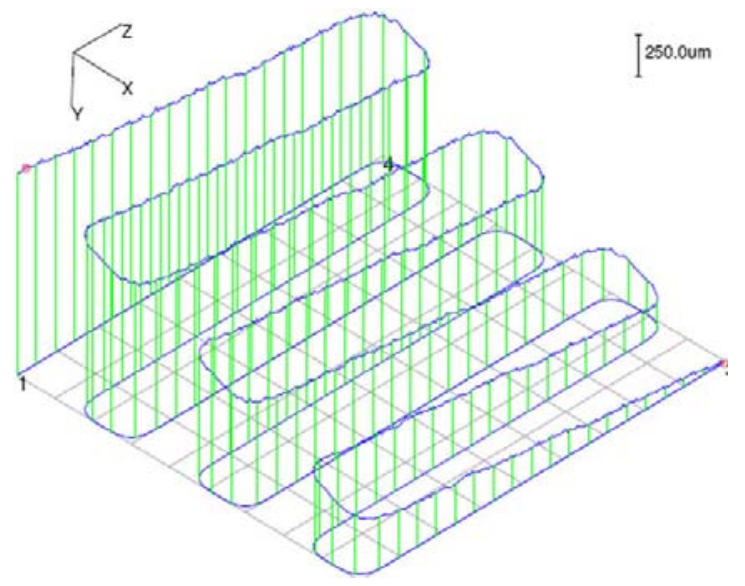

(b) parallelism

Figure 14 Flatness and parallelism of band sawing sliced surfaces (feed rate $=1.33$ $\mathbf{m m} / \mathbf{m i n})$

In comparison, wire sawing sliced surfaces had large flatness error but lower parallelism error, as shown in Figure 15. The flatness error of the wire sawing sliced surface was $129 \mu \mathrm{m}$ 
when the feed rate was $0.3 \mathrm{~mm} / \mathrm{min}$ and $106 \mu \mathrm{m}$ when the feed rate was $0.6 \mathrm{~mm} / \mathrm{min}$. The parallelism error between two wire sawing sliced surfaces was $0.232 \mathrm{~mm}$. Figure 16 shows the comparison of flatness and parallelism errors between wire sawing and steel band sawing.

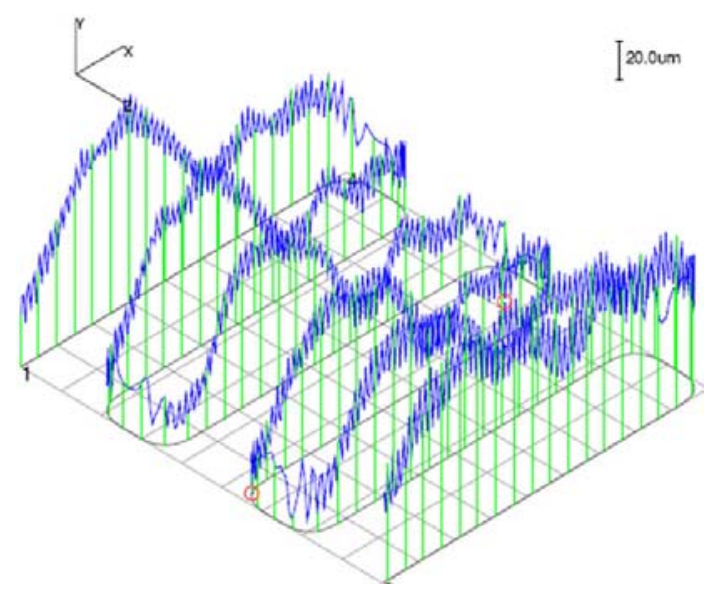

(a) Flatness

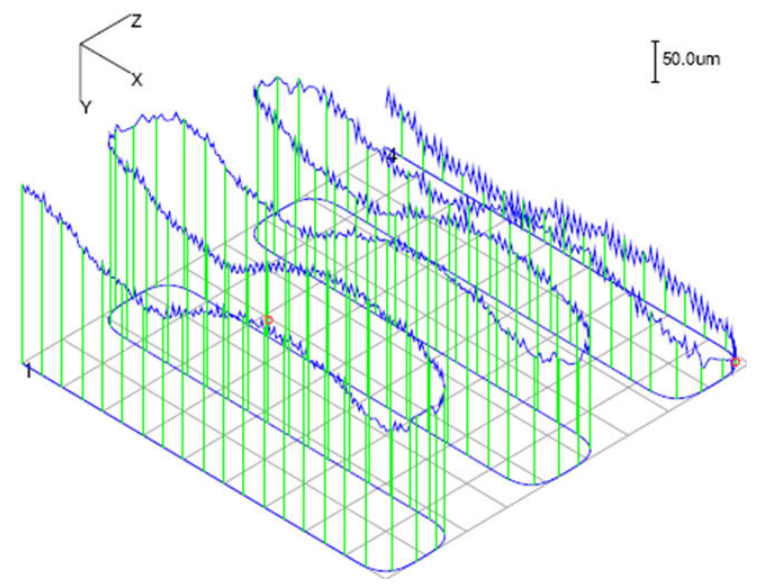

(b) parallelism

Figure 15 Flatness and parallelism of wire sawing sliced surfaces (feed rate $=0.6$ $\mathbf{m m} / \mathbf{m i n})$ 


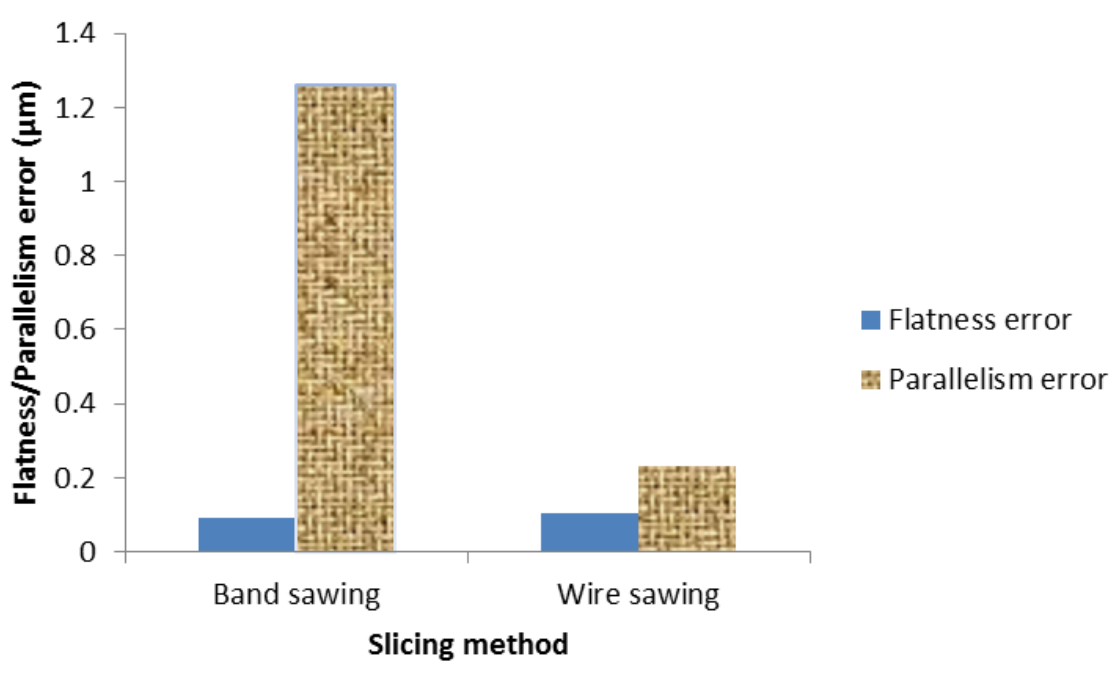

Figure 16 Comparison of flatness and parallelisn errors between band sawing and wire sawing

\subsection{Subsurface damage}

The effects of feed rate on subsurface damage in wire sawing (diamond grit size $=60 \mu \mathrm{m}$ ) are shown in Figure 17. As the feed rate increased from 0.2 to $0.6 \mathrm{~mm} / \mathrm{min}$, subsurface damage increased significantly. However, when the feed rate was in the range of 0.6 to 2 $\mathrm{mm} / \mathrm{min}$, subsurface damage remained relatively constant. Figure 18 shows subsurface damage caused by wire sawing (diamond grit size $=40 \mu \mathrm{m}$ ) when feed rate was $0.3 \mathrm{~mm} / \mathrm{min}$. The maximum value was $26.7 \mu \mathrm{m}$. In comparison, subsurface damage depth caused by wire sawing with larger diamond grit size $(60 \mu \mathrm{m})$ was much deeper than that with smaller diamond grit size $(40 \mu \mathrm{m})$. 


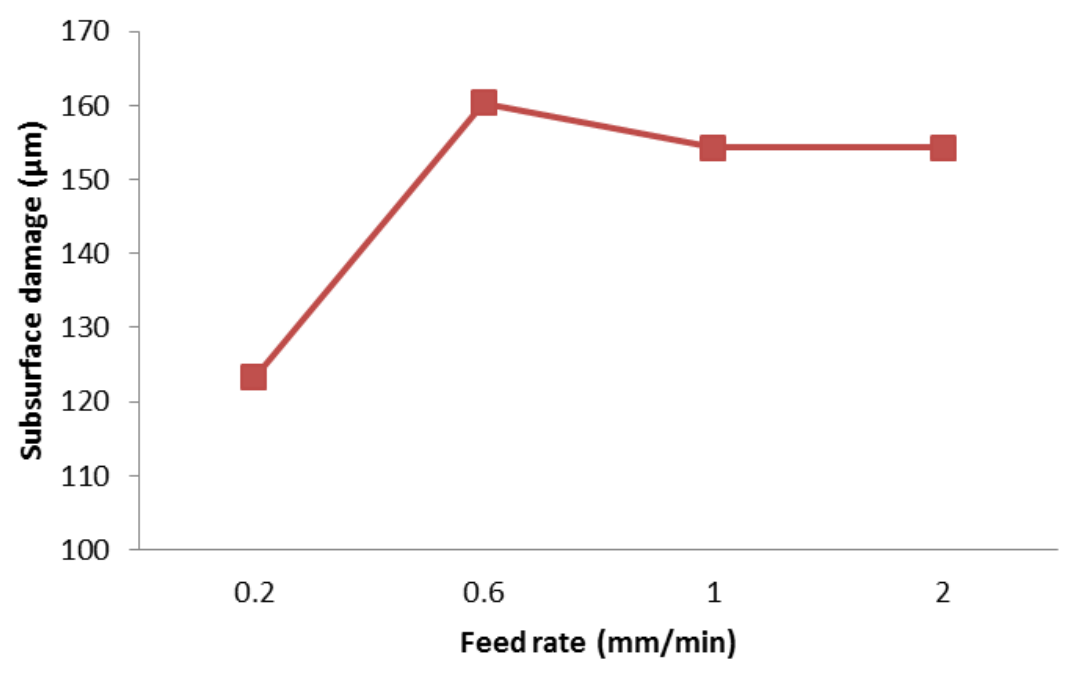

Workpiece size $=15 \mathrm{~mm} \times 6 \mathrm{~mm} \times 3 \mathrm{~mm}$, diamond grit size $=60 \mu \mathrm{m}$, wire speed $=60$ $\mathbf{m} / \mathbf{m i n}$

Figure 17 Effects of feed rate on subsurface damage in wire sawing

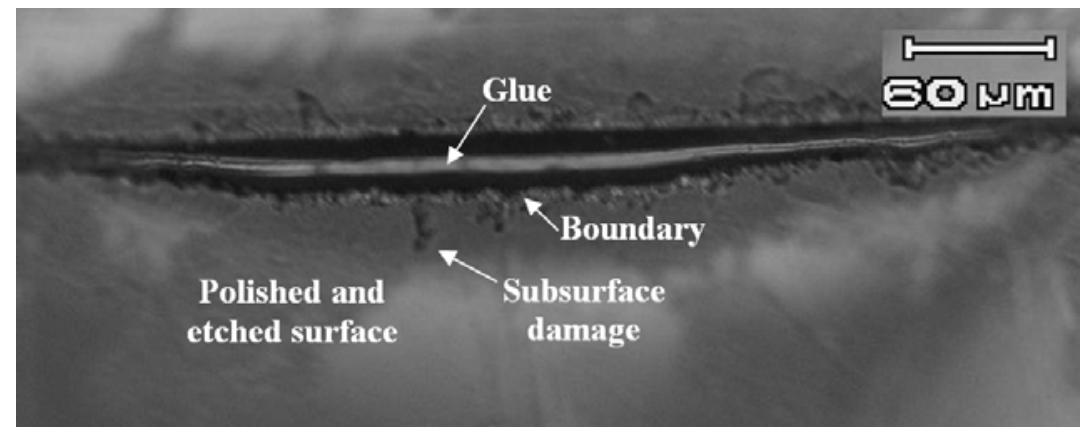

Workpiece size $=150 \mathrm{~mm} \times 105 \mathrm{~mm} \times 6 \mathrm{~mm}$, diamond grit size $=40 \mu \mathrm{m}$, feed rate $=$ $0.3 \mathrm{~mm} / \mathrm{min}$

Figure 18 Subsurface damage of wire sawing sliced surface

Figure 19 shows subsurface damage on KDP surfaces sliced by band sawing. As shown in Figure 20, the subsurface damage $(211 \mu \mathrm{m})$ caused by band sawing with teeth was much higher than that $(80 \mu \mathrm{m})$ caused by band sawing with plated diamond abrasives. 


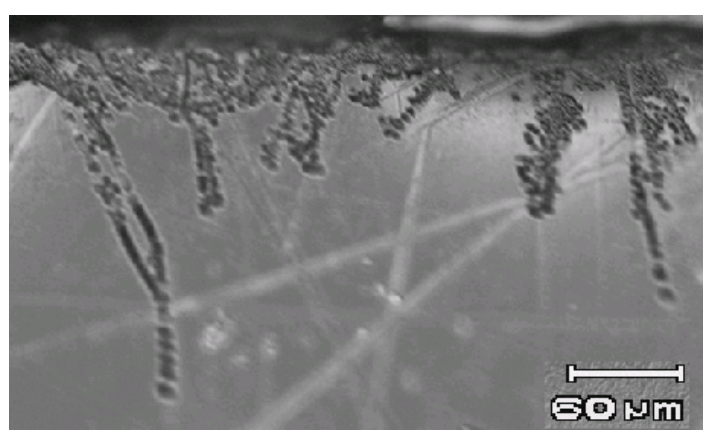

(a) Sliced by band saw with teeth

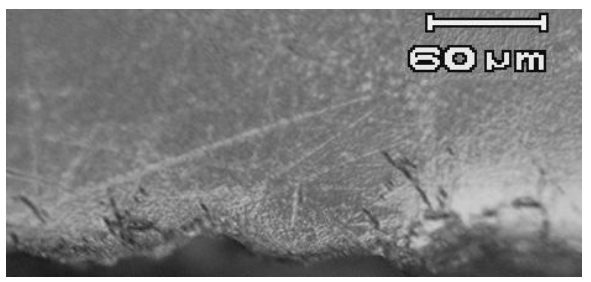

(b) Sliced by band saw with plated diamond abrasives

Figure 19 Subsurface damage of band sawing sliced surfaces

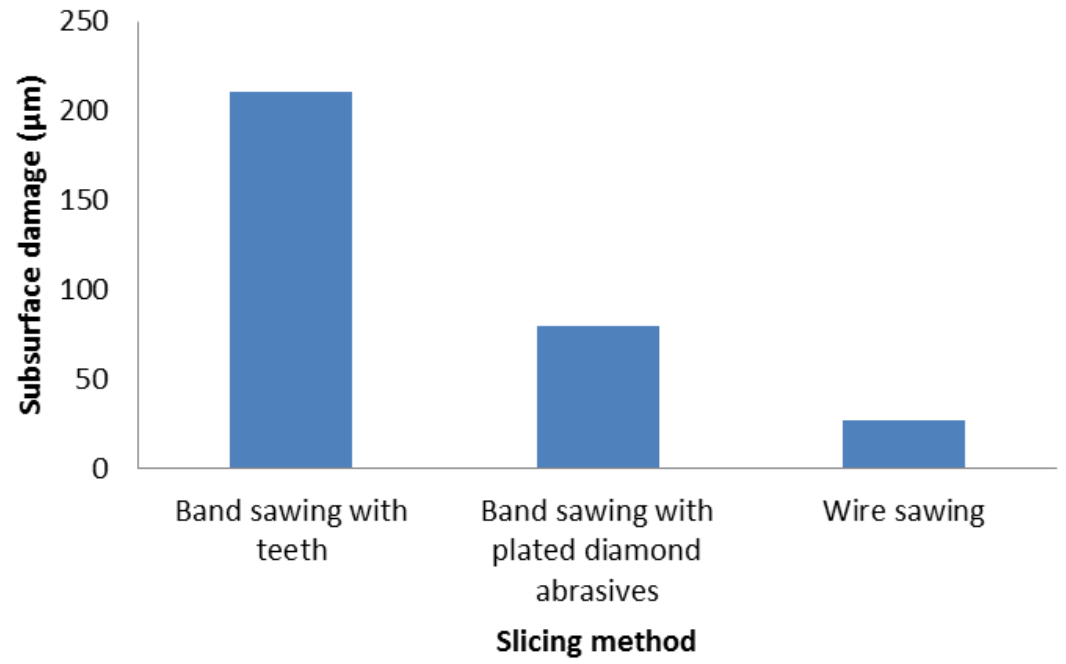

Figure 20 Subsurface damage comparison between different slicing methods

In order to remove all the subsurface damage and the geometrical imperfection (flatness and parallelism errors) induced by slicing, subsequent machining processes are needed after 
slicing. The amount of material to be removed would be determined by the largest of subsurface damage, flatness error, and parallelism error. For band sawing, since the largest was parallelism error $(1.260 \mathrm{~mm})$, the minimum amount of material that should be removed by the subsequent finishing processes would be $1.260 \mathrm{~mm}$. For wire sawing, the parallelism error was $0.232 \mathrm{~mm}$, therefore, the minimum amount of material that should be removed would be $0.232 \mathrm{~mm}$. In summary, wire sawing requires less material to be removed by subsequent finishing processes, which saves raw crystal material and reduces the machining time after slicing.

\section{Conclusions}

This paper reports an experimental investigation on wire sawing of KDP. Surface

roughness, flatness error, parallelism error, and subsurface damage were studied. Comparisons with band sawing were also made. Major conclusions are as follows.

(1) In wire sawing, as feed rate and diamond grit size increased, both surface roughness and subsurface damage increased.

(2) Compared with band sawing, wire sawing produced high flatness error but lower parallelism error.

(3) The amount of the material, required to be removed in subsequent machining processes after wire sawing, was much less than that needed after band sawing.

\section{Acknowledgements}

This work is supported by the National Natural Science Foundation of China (grant No. 50535020) and the State Key Lab of Crystal Materials of Shandong University (grant No. KF0904). 


\section{References}

[1] Bespalov, V. I., Bredikhin, V. I., Ershov, V. P., Zilberberg, V. V., and Katsman, V. I., 2001, "Gained Experience in Production of Wide-Aperture Optical Elements Using KDP, DKDP Crystals Rapid Growth Technology", Proceedings of SPIE (Prague, Czech Republic), 4424, pp. 124-128.

[2] Kalman, P., Juhasz, T., 1986, "Doubled Electro-Optic Light Shutter", Journal of Physics E: Scientific Instruments, 19(11), pp. 932-933.

[3] Yang, L., 2001, Advanced Optical Manufacturing Technology, Science Publishing House, Beijing, China, pp. 280-290.

[4] Chen, M. J., Pang, Q. L., Wang, J. H., and Cheng, K., 2008, "Analysis of 3D Microtopography in Machined KDP Crystal Surfaces Based on Fractal and Wavelet Methods", International Journal of Machine Tools \& Manufacture, 48, pp. 905-913.

[5] Hawley-Fedder, R., Geraghty, P., Locke, S., Mcburney, M., Runkel, M., Suratwala, T., Thompson, S., Wegner, P., Whitman, P., 2004, "NIF Pockels Cell and Frequency Conversion Crystals", Proceedings of SPIE (San Jose, California, USA), 5341, pp. 121-126.

[6] Fuchs, B. A., Hed, P. P., and Baker, P. C., 1986, "Fine Diamond Turning of KDP Crystals", Applied Optics, 25(11), pp. 1733-1735.

[7] Kozlowski, M. R., Thomas, I., Edwards, G., Stanion, K., Fuchs, B., 1991, "Influence of Diamond Turning and Surface Cleaning Processes on the Degradation of KPD Crystal Surfaces", Proceeding of SPIE (San Diego, California, USA), 1561, pp. 59-69.

[8] Wang, H. X., Wang, J. H., Sun, T., and Zhang, L. J., 2006, "Analysis on Some Problems in Ultra-Precision Machining of Potassium Dihydrogen Phosphate Crystals", Acta Armamentarii, 27(5), pp. 911-915. 
[9] 2007, "Ferro-Ceramic Grinding Incorporation, Ceramic Materials Properties Chart", Company brochure.

[10] Zhang, W. S., Zhang, F. H., and Dong, S., 2003, "Diamond Cutting of Optical Brittle Materials", Optics and Precision Engineering, 11(2), pp. 139-143.

[11] Wang, Z. K., 2003, "Slicing Equipments Development Status on IC Industry", Equipment for Electronic Products Manufacturing, 31(1), pp. 21-23.

[12] Buttner, A., 1985, "I.D. Sawing-Diameters Increase", Industrial Diamond Review, 45, pp. $77-79$.

[13] Pei, Z. J., Kassir, S., Bhagavat, M., and Fisher, G. R., 2004, "An Experimental Investigation into Soft-Pad Grinding of Wire-Sawn Silicon Wafers", International Journal of Machine Tools and Manufacture, 44, pp. 299-306.

[14] Zhang, B., Liu, W. T., Hu, X. D., and Li, W., 2008, "Application and Development of Wire Sawing Technology", Superhard Material Engineering, 20(1), pp. 45-48.

[15] Hardin, C. W., Qu, J., and Shih, A. J., 2004, "Fixed Abrasive Diamond Wire Saw Slicing of Single-Crystal Silicon Carbide Wafers", Materials and Manufacturing Processes, 19(2), pp. 355 367.

[16] Mclaughlin, H. B., 1985, "Precision Cutting with Diamond Wire Saw", Cutting Tool Eng., 37(3), pp. 17-19.

[17] Wu, D. J., Cao, X. S., Wang, Q. G., Wang, B., Gao, H., and Kang, R. K., 2008, "Damage Detection and Analysis of Machined KDP Crystal Subsurface", Optics and Precision Engineering, 15(11), pp. 1721-1726.

[18] Tonshoff, H. K., Schmieden, W. V., Inasaki, I., Konig, W., and Spur, G., 1990, "Abrasive Machining of Silicon", Annals of the CIRP, 39(2), pp. 621-630. 